\title{
Job satisfaction among nurses working in the private and public sectors: a qualitative study in tertiary care hospitals in Pakistan
}

This article was published in the following Dove Press journal:

Journal of Multidisciplinary Healthcare

3 January 2014

Number of times this article has been viewed

\section{Saima Hamid' \\ Asmat Ullah Malik ${ }^{2}$ \\ Irum Kamran ${ }^{3}$ \\ Musarat Ramzan ${ }^{4}$}

'Health Services Academy, Islamabad, Pakistan; ${ }^{2}$ Integrated Health Services, Islamabad, Pakistan; ${ }^{3} \mathrm{GIZ}$, Islamabad, Pakistan; ${ }^{4}$ Wah Medical College, Wah Cantt, University of Health Sciences, Wah, Pakistan
Correspondence: Saima Hamid Health Services Academy, Ministry of Health Services, Regulations and Coordination, Government of Pakistan, Near National Institute of Health, Park Road, Chak Shehzad, Islamabad, Pakistan Emailsaima_hamid@yahoo.com
Background: Many low and middle income countries lack the human resources needed to deliver essential health interventions. A health care system with a limited number of nurses cannot function effectively. Although the recommended nurse to doctor ratio is $4: 1$, the ratio in Pakistan is reversed, with 2.7 doctors to one nurse.

Methods: A qualitative study using narrative analysis was undertaken in public and private tertiary care hospitals in Pakistan to examine and compare job satisfaction among nurses and understand the factors affecting their work climate. Interactive interviews were conducted with nurses working with inpatients and outpatients.

Results: All of the respondents had joined the profession by choice and were supported by their families in their decision to pursue their career, but now indicated that they were dissatisfied with their jobs. Three types of narratives were identified, namely, "Working in the spirit of serving humanity", "Working against all odds", and "Working in a functional system and facing pressures of increased accountability". Nurses working in a public sector hospital are represented in the first two narrative types, whereas the third represents those working in a private sector hospital. The first narrative represents nurses who were new in the profession and despite hard working conditions were performing their duties. The second narrative represents nurses working in the public sector with limited resources, and the third narrative is a representation of nurses who were working hard and stressed out despite a well functioning system.

Conclusion: The study shows that the presence of a well trained health workforce is vital, and that certain aspects of its organization are key, including numbers (available quantity), skill mix (health team balance), distribution (urban/rural), and working conditions (compensation, nonfinancial incentives, and workplace safety). This study has identified the need to reform policies for retaining the nursing workforce. Simple measures requiring better management practices could substantially improve the working environment and hence retention of nurses.

Keywords: job satisfaction, nurses, health workforce, Pakistan

\section{Introduction}

Quality assurance in health includes all the actions taken to promote and enhance health care. ${ }^{1}$ Improvement in a health care delivery system involves not only adding new resources to a system, but also making changes within an organization to make the best use of resources, especially human resources. ${ }^{2-4}$ Humans perform optimally when satisfied with their work. Job satisfaction is determined by the degree to which the characteristics of a job fulfill a person's needs. The higher the balance of satisfaction over dissatisfaction, the more likely it is that an individual will play an active role in the fulfillment of organizational goals. ${ }^{2}$ 
The literature identifies several factors influencing levels of job satisfaction among nurses. Positive interpersonal relationships (loyalty, trust, sharing of common values) and quality of care have been associated with higher levels of job satisfaction. When nurses perceive patient care as being central to their work, their job satisfaction improves. Clearly defined roles and responsibilities, a balanced workload, and reward for effort are also related to higher levels of job satisfaction. ${ }^{5}$ In contrast with this, high patient to nurse ratios, dissatisfaction with the quality of work, poor leadership, and inadequate empowerment at work have been shown to be associated with burnout and poor job satisfaction. ${ }^{6,7}$

Laschinger et al showed that manageable workplace factors play an important role in influencing job satisfaction among new nurse graduates and lessen their likelihood of leaving in the first 2 years after graduation despite their motivation to work. ${ }^{8}$ Similarly, Gardner identified job stress as the strongest predictor of retention of new graduate nurses. ${ }^{9}$ Others have found that occupational stressors, burnout, lack of professional latitude, and role problems predicted nurses' decisions to quit their jobs. ${ }^{10-13}$

In Pakistan, the nursing profession has been experiencing a workforce shortage in recent years, making nurses a precious resource. The substantial shortage of nurses is mainly due to their emigration to developed countries in search of better pay and job prospects. The work-life issues threatening retention of nurses is of serious concern for health administrators. The Joint Learning Initiative Report in 2004 and the World Health Report in 2006 have listed Pakistan as one of the 57 countries with critical workforce deficiencies. ${ }^{14}$

Although there are 109 nursing schools and colleges in the country, shortage of nurses is still a problem of national concern with over 44,000 registered nurses in Pakistan. With a comparatively high nurse to population ratio ie, 1:3,043, the 965 largely urban-based hospitals are facing a shortage of this vital cadre of the health system. This dearth of the nurses becomes obvious in light of the reversed doctor to nurse ratio of 2.7:1 in the country. ${ }^{15} \mathrm{~A}$ health care system with a limited number of nurses cannot function effectively. While technology, diagnosis, and treatment are vital to the health system, without a strong arm of patient care provided by nursing staff, quality of care will remain a myth. Retention of nurses in the health care system is of concern to nursing communities throughout the world, especially in high income countries. The nursing shortage results in a "brain drain" of this vital source from low income countries. A range of factors has been shown to contribute to the shortage of nurses, including poor job satisfaction. ${ }^{6,7}$ It is thus imperative that job satisfaction in nurses is investigated, and at the same time, a comparison of the working environment for nurses in the private and public sector would provide better understanding and enable development of context-specific retention strategies.

Findings from studies in Pakistan reveal that the most dissatisfying factors at work and within the work setting are high workload, the stress associated with that high workload, biased nursing management, lack of appreciation or monetary incentives, and a rigid attitude on the part of nursing management. The most satisfying factors were working with an internationally reputable organization, getting positive feedback from patients, and the availability of necessary materials and equipment. ${ }^{16-18}$

This study was conducted in Islamabad to explore and compare the perception of job satisfaction in nurses working in public and private sector hospitals. It explores the various factors that contribute to job satisfaction in nurses and their subsequent retention in the various health care settings.

\section{Materials and methods}

A qualitative approach using narrative analysis ${ }^{19}$ was undertaken to identify the experiences of nurses working in private and public sector tertiary hospitals in Islamabad. "Narrative structuring entails the temporal and social organization of a text to bring out its meaning. It focuses on the stories told during the interview and works out their structures and plots. ${ }^{20}$ The analysis is a reconstruction of many stories told by different participants into a richer, more condensed, and coherent story. This method has been found to be appropriate for understanding how nurses working in tertiary care hospitals identify themselves as health care providers in their respective public and private sector settings.

\section{Study setting}

The study was carried out in two tertiary hospitals in Islamabad. Both are teaching hospitals with affiliated nursing schools. The public sector hospital includes only post graduate training in medicine, whereas the private sector hospital trains both medical students and graduates. Both the hospitals have allied medical and surgical specialties providing round-the-clock services. The clientele at the two hospitals varies primarily according to ability to pay.

\section{Study participants}

Nurses working in medicine, surgery, gynecology/obstetrics, the emergency room, and outpatient departments of the two hospitals (one government-run and the other a private hospital) were interviewed during their morning and evening 
shifts. Nurses who had been working at the hospital for at least the previous 6 months and who were willing to participate were included in the study.

\section{Data collection procedure}

During morning shifts, if nurses were free and given permission by administration, they would be asked to come for an interview. Individual interviews were carried out in the private space behind the nurses' stations in the public sector hospital, whereas a private room was provided by administration to carry out the interviews in the private sector hospital. Individual interviews were conducted until saturation was reached. Altogether, 41 interviews were conducted in the two hospitals. The principal investigator and two data collectors conducted the interviews in the local language. The data collectors were medical students. The principal investigator trained the data collectors during a one-day training session in which the data collectors were introduced to the objectives of the study, the method of data collection, and then discussed questions and the probes used in the field guide (see Supplementary material). This was followed by mock interviews. The interviews conducted by the data collectors were supervised by the principal investigator for the first week as a quality check and also to provide timely advice if needed.

The indepth interviews provided an opportunity for the study participants to describe their experiences openly and their perceptions about satisfaction with the work. The interview guide covered a broad number of areas, including positive and negative factors in the work place, work-related challenges, opportunities for professional growth, and relationships with coworkers. The nurses were encouraged to give detailed narratives of their experiences of working at the hospital and their interaction with patients and coworkers. The interviewer functioned as an interview guide and allowed the discussion to cover issues that the respondent deemed important. On average, an interview lasted 40 minutes. The interviews were audiotaped. In addition, the interviewers took notes and transcribed interviews within 24-48 hours. The interview style was exploratory and nonjudgmental.

\section{Data analysis}

Narrative analysis was carried out. The principal investigator and coinvestigators read the transcripts several times individually. The research team comprised four medical doctors (one male and three female) who had worked in the field of public health. All had experience in conducting research on different public health issues using quantitative and qualitative methods. Initially they read the transcripts independently for content and coherence. The team then worked together with a single interview at a time in the process involving purposeful search for stories. Transcripts rich in information were identified by the research team so that they could be used as paradigm cases. Condensed notes were inserted in a matrix on each of the narratives, noting the pattern of experiences, challenges at work, and coping strategies. During analysis, the research team alternated between being "narrative finders", ie, looking for the narrative contained in the interview, and being "narrative creators", ie, shaping the many different events into coherent stories. Thus, the analysis was a condensation or reconstruction of the many stories told by the different subjects into fewer richer, more condensed, and more coherent stories compared with the scattered stories of the separate interviewees. ${ }^{20}$ Hence, in this paper, the stories are constructed from the researchers' retellings of the interviewees' stories and quotations from the interviewees.

\section{Trustworthiness}

In this study, we achieved trustworthiness by adhering to the criteria of Lincoln and Guba. ${ }^{21}$ Credibility was ensured by including study participants of varied characteristics in terms of age, education, and marital status, and with diverse experience. In addition, investigator triangulation, field notes, audiotaping of interviews, and auditing of transcripts contributed to the dependability of the data. The research team read all the transcripts and the analysis was done over multiple meetings. Condensation of the interviews and exploration for similarities and differences in the experiences of the nurses was done independently by the research team initially, and after comparison and deliberation, the three narratives were finalized and consensus reached, thus ensuring conformability in our findings. A detailed description of the sample and the study setting can help the reader to assess to what extent the findings can be generalized (transferability) to nurses working in similar settings and situations in Pakistan.

\section{Ethical considerations}

The ethical review committee of the Health Services Academy, Islamabad, granted permission for the authors to carry out this research. Prior to contacting the nurses, administrative approval was obtained from the respective hospitals. Written consent was obtained from all participants and they were assured of confidentiality. Any information that could possibly identify a respondent was removed during analysis. 


\section{Results}

Forty-one nurses from private $(\mathrm{n}=15)$ and public $(\mathrm{n}=26)$ sector hospitals working in different wards were interviewed. The majority of nurses in both hospitals had some formal training after completing their BSc in nursing. The majority $(n=28)$ of the respondents were Muslim and the remaining 18 were Christian. Participants of married and unmarried status, with and without children, living in a nuclear or extended family, and a broad range of working experience (range 1-25 years) and age (22-45 years) were included from both hospitals to achieve a diverse group of participants (see Table 1 for details).

Three narrative types emerged from the data, ie, "Working in the spirit of serving humanity", "Working against all odds", and "Working in a functional system and facing pressures of high accountability".

Most of the "Working in the spirit of serving humanity" nurses had been working in the public sector hospital for less than 2 years and were motivated to serve humanity in a resource-limited setting. The "Working against all odds" nurses were dealing with problems in the resource-limited setting of the public sector hospital and taking responsibility for their duty of patient care despite nonavailability of resources and having to perform additional duties. The "Working in a functional system and facing pressures of high accountability" nurses worked in an environment that facilitated their work but at the same time put a lot of pressure on them to perform their duties efficiently. Table 2 gives an outline of the three narratives.

The findings highlight the major motivators and stressors experienced by the nurses at their workplace and how they

Table I Profile of respondents

\begin{tabular}{|c|c|c|c|c|}
\hline \multirow{2}{*}{$\begin{array}{l}\text { Characteristic } \\
\text { Education }\end{array}$} & \multicolumn{2}{|c|}{ Public n=I 5} & \multicolumn{2}{|c|}{ Private $\mathrm{n}=\mathbf{2 6}$} \\
\hline & & & & \\
\hline BSN & 5 & & 4 & \\
\hline BSN and additional training & 21 & & 16 & \\
\hline \multicolumn{5}{|l|}{ Religion } \\
\hline Islam & 10 & & 18 & \\
\hline Others & 16 & & 2 & \\
\hline \multicolumn{5}{|l|}{ Marital status } \\
\hline Married & 16 & & 13 & \\
\hline Unmarried & 10 & & 2 & \\
\hline \multicolumn{5}{|l|}{ Children } \\
\hline None & 0 & & 3 & \\
\hline I-2 children & 10 & & 3 & \\
\hline \multirow[t]{2}{*}{3 or more children } & 6 & & 7 & \\
\hline & $\begin{array}{l}\text { Mean } \\
\text { (SD) }\end{array}$ & Range & $\begin{array}{l}\text { Mean } \\
\text { (SD) }\end{array}$ & Range \\
\hline Experience in years & $10(7)$ & $\mathrm{I}-25$ & $5.8(5.7)$ & $\mathrm{I}-25$ \\
\hline Age (years) & $32(4.5)$ & $20-45$ & $35(7)$ & $22-45$ \\
\hline
\end{tabular}

Abbreviations: BSN, BSc in nursing; SD, standard deviation. addressed the various challenges while performing their duties. The three narrative types were mainly based on analysis of interviews from the 41 participants. The first narrative type, ie, "Working in the spirit of serving humanities" is based on eleven interviews with nurses working in the public sector (seven with experience of less than 2 years and four with at least 5 years of experience) and one working in the private sector. The second narrative type, ie, "Working against all odds" reflected the identities of 15 nurses working in the public sector. The third narrative type, ie, "Working in the functional system and facing pressures of high accountability" reflected the identity of 14 nurses working in the private sector. For the first and third narratives, one interview with the richest information selected as a framework and selected sections from other interviews were inserted in the framework as coherent stories, whereas for the second narrative the framework is based on three interviews supplemented with others.

\section{"Working in the spirit of serving humanities"}

All the participants had joined the nursing profession by choice. This narrative type, which we have labeled "Working in the spirit of humanity", is represented here by "Musarat", a 21-year-old nurse who completed her nursing training a year ago. She has recently been married and has no children, and her in-laws support her in her work. Her husband is working for the government and has a decent salary. This young couple lives with the husband's parents and younger four siblings, and provides substantial financial support for the running of the house and sending the siblings to school. Musarat has an aunt who is a nurse and Musarat has always wanted to be like her and serve humanity:

I know the importance of this profession. I believe it is the noblest profession.

\section{Benefits of being a nurse}

Musarat is happy to have been receiving her stipend since her first year of training as a nurse and has not been dependent on her family ever since. By virtue of working at the hospital, she had ensured better access to health care for her entire family. She can personally bring any family member who is sick to the hospital and the doctor on duty would treat the patient on her reference. She believes that the best part of her profession is looking after the sick and helping them to get well.

One participant contributing to this narrative admitted that she liked the learning environment of her work. 
Table 2 Outline of narrative types

\begin{tabular}{|c|c|c|}
\hline $\begin{array}{l}\text { Working in spirit of serving humanity } \\
n=12\end{array}$ & $\begin{array}{l}\text { Working against all odds } \\
n=I 5\end{array}$ & $\begin{array}{l}\text { Working in a functional system and } \\
\text { facing pressures of high accountability } \\
n=14\end{array}$ \\
\hline $\begin{array}{l}\text { - Young and motivated nurse } \\
\text { - Seeing sick recover gratifies her } \\
\text { - Better access to care for her and family } \\
\text { - Information source is medical representatives } \\
\text { - No respect by patients but continues to work } \\
\text { - Good relationship with administration and wants } \\
\text { to have opportunities in future } \\
\text { - Coping with long working hours with support } \\
\text { from family } \\
\text { - Get allowances as part of salary (uniform and } \\
\text { ration allowance) }\end{array}$ & $\begin{array}{l}\text { - Demotivated } \\
\text { - Put off by patients' disrespectful behavior } \\
\text { - Media does not portray a good picture } \\
\text { of nurses and it should } \\
\text { - No security at night } \\
\text { - Shortage of staff and supplies } \\
\text { - Grade not improved even after years } \\
\text { - of service } \\
\text { - Long working hours and not enough } \\
\text { - Has permanent job and pension } \\
\text { - Has access to doctors even though } \\
\text { drugs have to be purchased } \\
\text { - Working in private sector to supplement } \\
\text { - Less opportunities for training } \\
\text { - No overtime or working for holidays }\end{array}$ & $\begin{array}{l}\text { - Motivated } \\
\text { - Enjoys work in a clean and safe } \\
\text { environment (security, supplies, } \\
\text { equipment) } \\
\text { - Respected by doctors and coworkers } \\
\text { - Compensation for overtime not } \\
\text { satisfactory } \\
\text { - Support from other departments, eg, } \\
\text { - housekeeping } \\
\text { - } \text { their toes } \\
\text { - Renewal of contracts based on appraisal } \\
\text { - } \text { reports } \\
\text { - Instervice training } \\
\text { - Recognition and award system functional } \\
\text { - Responsibilities clearly defined }\end{array}$ \\
\hline
\end{tabular}

The main source of information identified was that provided by medical representatives:

We learn by being present in the learning environment of a hospital.

Six participants liked their friendly environment and working as a team:

We get respect from patients, doctors, and colleagues. As soon as I enter the hospital I start feeling proud of my work.

\section{"Working against all odds"}

Many nurses working in government-run hospitals had strong feelings about working under harsh conditions. This narrative type, ie, "Working against all odds" is represented here by "Saba", and is based on three condensed interviews and shaped with additions from twelve other interviews. Most of the interviewees had experience of working in the government setting for more than 5 years.

\section{Image of nursing profession in the sociocultural context}

Saba is married and has five children. She earns the equivalent of USD 110 per month and is satisfied with her salary. Her husband works at a government office and they are able to have a decent life and send their children to school. It becomes difficult to make ends meet when they have to send money to their families to support them. Saba believed that nurses are not respected by patients and their relatives, or by the junior doctors. She thinks that the media do not portray a good image of nurses, which further reinforces the poor behavior of the public towards nurses. At times, the behavior of doctors and managers can be insulting, and takes place in front of patients, which is very disheartening and embarrassing. She believes that some administrative personnel favor particular nurses who know how to develop a good relationship with them and keep them happy. She feels that there is a lot of paperwork to attend to, along with maintaining inventories, eg, when adequate supplies are not provided in a timely manner she has to maintain the $\log$ books, place orders, and run around to obtain them. She feels that her energies could be better spent on her primary duties to ensure better care of the patients. Even security is an issue when she is on night shift. Sometimes the guard is not on duty. After complaining to the hospital administration multiple times, young nurses are not put on night duty alone. Further, senior married nurses like Saba have to attend to about 40 patients by themselves and deal with some very difficult patients and their relatives, not to mention having limited access to supplies at night. Saba feels that a general lack of respect makes her job difficult and unpleasant:

Many people see nurses talking to the patients and think that they are flirtatious and do not deserve respect. Many patients treat us like servants and think we are there for their entertainment.

Saba feels strongly that patients, managers, and doctors do not appreciate the circumstances under which a nurse 
works, especially when the hospitals are understaffed and nurses overburdened. At times, Saba would be the only nurse on a ward with six doctors on duty, all of whom would give her a lot of instructions and then leave. She has to supervise junior nurses and maintain medical records for all patients, but has never been consulted during clinical rounds:

Everything that goes on in this ward is my responsibility. I want to spend most of my time in patient care as looking after the patients and providing clinical care (to give daily medicines, maintain the record of vitals of the patients and take necessary action and call the doctors as needed), but I have to maintain the duty roster, store's inventory, supervise the sanitary worker and ward boy, and do housekeeping like ensuring clean linen for patients...

Every item, from the switchboard to the fans, is my responsibility. If anything gets lost I would be held responsible. At times I can't even sleep at night because of the tension.

There is no system for addressing our complaints and mostly for any complaint filed by the patients, we the nurses, end up apologizing. There is a lack of transport and residential facilities. We were told that the pay scale would be improved but we are still waiting.

Saba feels strongly that the doctors could improve the working conditions of nurses substantially by speaking politely to them and giving them due respect. The nurses could also benefit if the doctors could hold lectures, seminars, and courses for them.

Dissatisfaction with remuneration was expressed by all participants. One nurse reported that, after 25 years, she still earned the equivalent of USD 110 per month. The participants were unhappy about the long working hours. Many complained about the 12-hour shifts they had to work because of a shortage of staff. They were not left with enough time to attend to their family or anything else.

At the end of the day it is the mental tension here that drains you.

\section{Benefits of working in a government hospital}

Saba is pleased that at least she has a permanent government job and will get a pension after retirement. By virtue of her presence at the hospital, she has access to doctors and drugs when needed for her family. She has availed herself of 3 months of maternity leave for all her children. Her mother or mother-in-law always comes to help her with her children. Saba is working extra shifts at a private hospital to supplement her earnings, mainly because she has to educate all her children. Although she is exhausted during her duties in a government hospital, she believes that she can cope with the work. Saba hopes that soon she might be selected for inservice training, but at the same time recognizes that her chances are bleak:

The administrators inform us of training opportunities after the date for applications has passed. They do not want any one of us to attend - so who will work in the hospital if we go?

Some nurses from the same hospital have been selected for Haj duty (ie, when one is officially send to Mecca as a part of team providing medical services for Pakistanis during the pilgrimage). The team members have the opportunity to make the pilgrimage themselves while on duty, so Saba hopes that someday she too might be selected for it. Saba can take leave, but to get leave sanctioned for personal reasons is a Herculean task due to shortage of staff.

\section{"Working in a functional system - and facing pressures of high accountability"}

Of the 14 nurses working in the private hospital, nine had experience of working in a government sector hospital. All had chosen to become nurses and were satisfied that they had taken up such a noble profession. The narrative case, which we label "Working in a functional system - and pressures of high accountability" is thus characterized by the experiences of nurses working in a well equipped and functional private sector hospital. "Huma" is a 28-year-old nurse who narrated her story as follows.

\section{Benefits of working in a private hospital}

Huma is happy working in this hospital as she has worked in a government hospital before. She feels secure even when on night duty. It is easier for her to work in this hospital as her tasks are clearly defined.

I get a good pay almost double of what I used to earn in the government hospital. Other departments such as housekeeping and maintenance cooperate with me so I do not waste a lot of time ensuring that their work is done. Moreover, the patients and doctors respect me here. My opinions are valued here. The doctors and administration listen to us most of the time. It is good to work here as this hospital is well equipped and provides quality care and I get a chance to work with the latest equipment available at the hospital. We are given free transport facilities and all nurses get a free uniform and a pair of shoes every year. Our senior nurses are respectful and ensure that we get recognition 
for good performance. I once had a personal problem and needed urgent leave. My senior nurse fully supported me and her empathy helped me through the bad patch. Working in this hospital is a good learning experience as the training one receives here is at par with international standards. We learn new techniques. There is team work, and mutual respect with colleagues and doctors makes working here worthwhile. The environment is neat and clean here.

There are opportunities for Huma for in-service education. If she continues to work in this hospital for a few years she has greater chances of getting a good job abroad. The administration has never skipped the salary of even a day. All overtime is taken into account and the pay given on time. If there is any non-functional equipment and the complaint is registered it is repaired timely. Huma has never experienced shortage of supplies during her work at the hospital. All the departments work in harmony.

I am happy that since I work at the hospital my family and I get medical coverage in this private hospital through an insurance scheme. Free transport is a big benefit. You know how things are these days. "Izzat say atayhainaurizzat say jatayhain" (We come and leave the hospital respectfully). All promotions are performance based and employees' appraisal reports. There is certainly a career path in this hospital.

\section{Organizational pressures of working in a private hospital}

The nurses shared that they had to face the patients' complaints even when complaints are directed at others such as the doctors, eg, if the doctors did not write the notes properly, then they had to face the music and apologize to the patients. Often the nurses were blamed for things beyond their control. They faced organizational pressures of working in a private hospital. Even though working in this hospital took a heavy toll on the nurses, most felt good to work there as once they got promoted to being a manager, the salary would improve three-fold at least, of what one earns in the public sector.

My friends working in the public sector do not take as much responsibility as I do. When they leave for home they leave all the tensions behind. For the amount of tension and workload that we take we are not paid enough. A better salary would help especially when we work so hard all the time. The time spent on duty is always intense. Because there is accountability for every single action, I really get tired and am over-worked. In the end no one else suffers; not the kids, not your husband and not your household. But you lose out on yourself. You never have enough time for yourself.
All participants mentioned that there were training opportunities at the hospital that some of them had taken up. Two mentioned that there was an allowance for higher study, even though none of the respondents had actually received such support. All agreed that the "employee of the month" was a good incentive to work for and that the monetary gain was attractive. All the nurses mentioned that initially they had to work tough shifts and prove their worth to the hospital, and as they became more senior and moved up in the hierarchy, the working hours improved. One nurse said that she liked the fairness of the system. A proper channel existed to address their problems.

The private hospital had a policy of nurses working no more than 48 hours per week. Anyone working beyond that was paid overtime. Because of overtime, these nurses were able to earn better than the nurses working in the public sector hospital. None of the nurses could work for more than 12 hours a day. Those working during holidays were either paid overtime or given a day off as compensation. As far as vacations were concerned, there were generally no problems. The nurses worked these out amongst themselves and administration only came in when they needed to provide a substitute. Most of the nurses found the working hours tough because they had to put in more than regular 8-hour shifts because of shortage of staff. Although they had a half-hour lunch break, they often had to miss it because of work overload. Sometimes they were called in over the weekends as well, which was exhausting. One said that their work burden worsened when one nurse went on leave and the others had to cope with the extra work. Nurses worked in three shifts, ie, from 6:45 am to $3 \mathrm{pm}$, from $3 \mathrm{pm}$ to $11 \mathrm{pm}$, and from $11 \mathrm{pm}$ to $7 \mathrm{am}$.

Many of the nurses said that the doctors were very helpful in developing a healthy atmosphere and environment, and that they respected them. Most nurses had no problem with the senior doctors and consultants, but some felt that the juniors could be very rude at times. Twelve of the participants were satisfied with the recognition they got from the hospital. They were appreciated and awarded certificates for "best nurse" and "employee of the month", inclusive of a monetary award. At the time of annual appraisal, the nurses received certificates, and their salary packages were revised based on performance and they were given bonuses. Many said that they received letters of appreciation annually. However, failing to perform could result in one's contract being terminated. This put a lot of pressure on the nurses during their daily work.

The majority of the nurses said that they did take up professional opportunities, such as seminars, short courses, 
and lectures from the doctors (within the hospital), which were given on a seniority basis. The roles and responsibilities were defined for all nurses according to the level at which they worked. The bedside nurses were responsible for patient care. Senior nurses had to guide and supervise the juniors, and the juniors had to report their daily progress to the seniors. Another nurse said that:

\begin{abstract}
My job is group guidance, execution of orders of the doctors and managers, supervision of nurses, maintenance, and cleanliness activities. We make the duty roster, accompany doctors on the rounds, and carry out physicians' orders. We check whether the patients' bills have been filed correctly and ensure that all procedures have been carried out on time. We ensure that the patient is provided with effective and safe high quality care and that infection control is maintained.
\end{abstract}

All the nurses said that their responsibilities differed according to the level at which they worked. A manager had a team of nurses working under her to complete all tasks and a strict monitoring system was in place. All nurses reported that the workload was difficult to cope with and exhausting. Some said that administration should be more helpful and cooperative and not be on the lookout for any shortcomings in their work. The patients treated them as their servants. The nurses said that administration really should try to solve this problem. One nurse said:

This is the reason why many members of staff have also started to leave the hospital.

\section{Discussion}

The findings of this study indicate that nurses in both the private and public sectors were dissatisfied with their jobs, but their grievances differed, as depicted in the three narratives. Those working in the public sector for more than 5 years were not satisfied with their work. Although most of the respondents had chosen the nursing profession to serve humanity and were supported by their families in their decision to pursue their career, many were now struggling to keep up with their job responsibilities.

As regards the working environment, nurses in both the public and private sectors were exposed to completely different situations. In the public sector hospital, as reflected in the first two narratives, the nurses worked with limited resources, and wanted the respect of doctors, patients, and their relatives. This finding is similar to that of other studies in Pakistan and Lebanon showing that lack of respect is associated with poor job satisfaction. ${ }^{16,22-24}$ The literature shows that interpersonal relationships play an important role in job satisfaction of nurses and their retention. ${ }^{25}$ Nurses in the public sector believed that if the senior doctors respected them and did not insult them in front of patients, the others would automatically respect them, including the junior doctors. In the private hospital setting, because administration recognized the importance of nurses, they were respected more. Since most of the respondents had previously worked in the public sector, they could compare the difference in the two environments and were more satisfied than their counterparts in the public sector.

Nurses in the government sector were working under harsh conditions and were dissatisfied with the remuneration that they got for their services. Because of staff shortages, the nurses were overworked in the government hospitals (narratives 1 and 2). Even the nurses reflected in the third narrative and working in a good hospital environment hoped for better salaries for the amount of stress they were subjected to on a daily basis when performing their duties. They knew that their job prospects abroad would be better if they had experience of working in a private hospital, so despite being at high risk of burnout, they endured the workload.

All narratives show that in-service training was desired by all participants. The participants in narrative 3 , working in the private sector hospital, received regular training. These nurses used the hospital as a platform to obtain employment abroad. The private sector provided opportunities for growth based on performance. The job responsibilities of the nurses were the same in the two sectors; however, there was more accountability in the private sector and clearly defined roles facilitated their work.

In contrast, many nurses in the public sector were still working in the same post after years of service. Training courses for nurses were hard to come by in the public sector. Because of the shortage of nurses, administration preferred not to send them on training courses. Our study shows that the private sector attracts nurses from the public sector by offering better pay and better working conditions. In the public sector, the majority of nurses were neither promoted after many years of service nor was their pay structure affected by performance. Lack of career progress contributed to dissatisfaction as well. Nurses in the public sector did not have a mechanism whereby doctors could contribute to training for nurses. Doctors willing to contribute in this way did so informally. The main sources of information for nurses were drug representatives. This clearly shows a gap in their training needs. Even simple measures, such as including 
them in clinical rounds, could potentially contribute to their satisfaction at work.

The main difference in the working environment between the two hospitals was in the organizational climate. This is probably due to the conceptual difference between the two types of hospitals, ie, where one is profit-driven and needs to provide quality service to stay in business, whereas the latter has no such drive and is dependent on government funding. The World Health Organization "Framework for Action" describes six clearly defined building blocks that together constitute a complete health care system, with the health workforce being an important component. It is the multiple relationships and interactions between these components, ie, how one affects and influences the others, and is in turn affected by them, that convert these components into a system. Leadership and governance play an important role in creating a favorable environment in which human resources are well distributed and a balanced skill mix is available to deliver health care efficiently. Nurses who had less than 2 years of experience were motivated to work within constraints (narrative 1); however, it is essential to make organizational changes to retain them, as reflected in narrative 2. Simple strategic measures can ensure retention of such a precious workforce. Laschinger ${ }^{8}$ has also highlighted the need to focus on retention of fresh graduates in the system by taking simple strategic measures such as orientation and preceptorship programs, and developing technical skills. Retaining graduate nurses is an important strategy for addressing the nursing shortage and for sustaining the future of the profession. In Pakistan in particular, the salary structure needs to be improved to retain this workforce in the country.

Nurses in the private sector were maintaining the patient to nurse ratio standards. This could not explain the pressures the junior nurses were experiencing. One team leader had bedside nurses working under her. They would work as a team and attend to all tasks related to patient care. There was constant supervision and accountability of these nurses, and because the newly inducted nurses were still learning, the trained ones were stressed out at work. In contrast with this, nurses in the public sector had to look after 25-40 patients during night shifts. In the private sector, because of the strict supervision and increased accountability, the nurses were stressed out. This finding is consistent with previous studies where job stress has been negatively associated with job satisfaction. Aiken et $\mathrm{al}^{6}$ has addressed the same issue and highlighted the need for adequate staffing. Hospital beds had increased in number without a subsequent increase in posts for nurses in the government hospital. Our study has identified areas for improvement in the working environment of the nurses to optimize their functioning.

\section{Conclusion}

Nursing is an integral part of the health care system globally. This study has identified a need to reform policies for the nursing profession in Pakistan, because nurses working in the private and public sectors are not satisfied with their jobs. Simple evidence-based, low-cost strategic measures could be taken to improve the retention of nurses. Investment in strategies to reduce the exhaustion and ineffectiveness associated with increased work pressure are essential if nurses are to experience work that is satisfying and enjoyable. A cohesive and committed workforce could then function more efficiently and effectively. Hospitals should invest in nurses through staff development, orientation programs, and an improved work environment as such measures are more cost-effective in the long term.

\section{Acknowledgments}

The authors appreciate the support extended by the hospital administrators for facilitating interviews with the respondents in this study. The authors would also like to thank all nurses who agreed to participate. This research was supported by a small grant from Deutsche Gesellschaft für Internationale Zusammenarbeit (GIZ), Pakistan.

\section{Author contributions}

All authors contributed substantially to the conception and design of the project. SH collected the data, supervised the data collection team and transcribed it. All authors verified the transcripts for any inconsistencies or redundancies. The decision about saturation of the data was based on consensus of all the authors. All authors contributed to analysis and interpretation of data. SH took a lead in drafting the manuscript and revising it based on the the critical feedback from all authors. All authors have read the final draft and have approved it.

\section{Disclosure}

The authors declare no competing interests in this work.

\section{References}

1. Massoud R, Askov K, Reinke J, et al. A Modern Paradigm for Improving Healthcare Quality. Bethesda, MD: Published for USAID by the Quality Assurance Project; 2001.

2. Bahamon C, Dwyer J, Buxbaum A. Leading a change process to improve health service delivery. Bull World Health Organ. 2006;84(8): 658-661. 
3. De Savigny D, Adam T. Systems thinking for health systems strengthening. Geneva, Switzerland: World Health Organization; 2009. Available from: $\mathrm{http}: / / \mathrm{www}$.unicef.org/protection/World_report_on_ disability_eng.pdf. Accessed November 3, 2013.

4. Green A. An Introduction to Health Planning in Developing Countries, Volume 2. Oxford, UK: Oxford University Press; 1999.

5. Utriainen K, Kyngäs H. Hospital nurses' job satisfaction: a literature review. J Nurs Manag. 2009;17(8):1002-1010.

6. Aiken LH, Clarke SP, Sloane DM, et al. Nurses' reports on hospital care in five countries. Health Aff (Millwood). 2001;20(3):43-53.

7. Miller JF. Burnout and its impact on good work in nursing. $J$ Radiol Nurs. 2011;30(4):146-149.

8. Laschinger H. Job and career satisfaction and turnover intentions of newly graduated nurses. J Nurs Manag. 2012;20(4):472-484.

9. Gardner DL. Conflict and retention of new graduate nurses. West J Nurs Res. 1992;14(1):76-85.

10. Dolan S, Ameringen M, Corbin S, Arsenault A. Lack of professional latitude and role problems as correlates of propensity to quit amongst nursing staff. $J$ Adv Nurs. 1992;17(12):1455-1459.

11. Nabirye RC, Brown KC, Pryor ER, Maples EH. Occupational stress, job satisfaction and job performance among hospital nurses in Kampala, Uganda. J Nurs Manag. 2011;19(6):760-768.

12. Flinkman M, Leino-Kilpi H, Salanterä S. Nurses' intention to leave the profession: integrative review. JAdv Nurs. 2010;66(7):1422-1434.

13. Hussain A, Rivers PA, Glover SH, Fottler MD. Strategies for dealing with future shortages in the nursing workforce: a review. Health Serv Manage Res. 2012;25(1):41-47.

14. Joint Learning Initiative. Human Resources for Health: Overcoming the Crisis. Cambridge, MA: Harvard University Press; 2004.

15. Nishtar S, Boerma T, Amjad S, Alam AY, Khalid F, Mirza YA. Pakistan's health system: performance and prospects after the 18th Constitutional Amendment. The Lancet. 2013. 381: 2193-2206.
16. Bahalkani HA, Kumar R, Lakho AR, Mahar B, Mazhar SB, Majeed A. Job satisfaction in nurses working in tertiary level health care settings of Islamabad, Pakistan. J Ayub Med Coll Abbottabad. 2011;23(3): 130-133.

17. Kumar R, Ahmed J, Shaikh BT, Hafeez R, Hafeez A. Job satisfaction among public health professionals working in public sector: a cross sectional study from Pakistan. Hum Resour Health. 2013;11(1):2.

18. Khowaja K, Merchant RJ, Hirani D. Registered nurses perception of work satisfaction at a tertiary care university hospital. J Nurs Manag. 2005;13(1):32-39.

19. Riessman CK. Narrative Analysis, Volume 30. Thousand Oaks, CA: Sage Publications; 1993.

20. Kvale S. Interviews: An Introduction to Qualitative Research Interviewing. Thousand Oaks, CA: Sage Publications; 1996.

21. Lincoln YS, Guba EG. Naturalistic Inquiry. London, UK; Sage Publications; 1985.

22. Yaktin US, Azoury NB-R, Doumit MA. Personal characteristics and job satisfaction among nurses in Lebanon. J Nurs Adm. 2003;33(7-8): 384-390.

23. Adams A, Bond S. Hospital nurses' job satisfaction, individual and organizational characteristics. J Adv Nurs. 2000;32(3):536-543.

24. Upenieks VV. The interrelationship of organizational characteristics of magnet hospitals, nursing leadership, and nursing job satisfaction. Health Care Manag (Frederick). 2003;22(2):83-98.

25. Wilson B, Squires M, Widger K, Cranley L, Tourangeau A. Job satisfaction among a multigenerational nursing workforce. J Nurs Manag. 2008;16(6):716-723.

26. Tuckett AG. Part II. Rigour in qualitative research: complexities and solutions. Nurse Res. 2004;13(1):29-42. 


\section{Supplementary material \\ Field guide for the interview}

Introduce yourself and explain the objectives of the research project. Thank the interviewee for consenting to participate in the study and for giving you time. Mention that the interview would last from 45-60 minutes.

Ask for the general information and then start with the interview with the respondent.

Demographic profile

Name

Place of posting

Designation

Experience in years

Age

Education

Religion

Marital status

Number of children

\section{Questions}

1. How and why did you take up nursing as a profession?

2. How would you describe your experience of working in this hospital?

What do you think are the good things in your working environent? (probe for motivators at work, responsibilities and role of autonomy at work, decision-making)

What are the bad things in your working environment? (probe for demotivators at work)
3. What are the benefits of working here? What are the working hours like?

4. What type of compensation do you get, if any, for working over weekends and national holidays? How do you get vacations?

5. What is the attitude of the administration towards your work and other related issues? (compensation for services, incentives both monetary and nonmonetary, professional growth opportunities, rewards for recognition of your work)

6. How do you regard the doctor-nurse interaction in this hospital?

7. What role can/do the doctors and administration play in improving the working conditions for the nurses?

8. What are the issues that need to be addressed to improve the job satisfaction of nurses? Can you make suggestions?
Journal of Multidisciplinary Healthcare

\section{Publish your work in this journal}

The Journal of Multidisciplinary Healthcare is an international, peerreviewed open-access journal that aims to represent and publish research in healthcare areas delivered by practitioners of different disciplines. This includes studies and reviews conducted by multidisciplinary teams as well as research which evaluates the results or conduct of such teams or health-

\section{Dovepress}

care processes in general. The journal covers a wide range of areas and welcomes submission from practitioners at all levels, from all over the world. The manuscript management system is completely online and includes a very quick and fair peer-review system. Visit http://www.dovepress. com/testimonials.php to read real quotes from published authors. 